\title{
Case Study Report: Plagiarism
}

\author{
Xuejuan Luo \\ School of Foreign languages, Qinghai Nationalities University, Xining, 810007, China
}

\section{Keywords: Plagiarism, Academic phenomenon, Submit, Solution}

\begin{abstract}
Plagiarism, a general academic offence, is to take words and ideas from someone else's work and use them in one's own academic assignment without admitting one's doing that. Plagiarism is also considered a moral offense against anyone who has provided the plagiarist with a benefit in exchange for what is specifically supposed to be original content. This report aims to examine the issue of plagiarism by discussing the case of Igor, a Russian student in the U.S, who committed plagiarism by submitting his friend's research paper as his own. Three possible solutions are suggested and evaluated. Consequently, the most appropriate one, which is justified, is that Igor confronts the problem by apologizing to the professor and asking for a resubmission. Then in the conclusions and recommendations some plagiarism problems are pointed out and the relevant measures of preventing plagiarism are presented.
\end{abstract}

\section{Introduction}

Plagiarism is a common academic phenomenon in colleges, universities as well as in the area of public printing (Schulman, 1998). People may commit plagiarism by using others' thoughts or their works with no proper credit and acknowledgement of authorship (Martin, 1992). Plagiarism is considered to be dishonest conduction of someone else's thoughts and ideas. If one needs to plagiarize, he/she has to state officially where the sources of the ideas and theories come from. He/she must be responsible for all those facts included. Evidences for those points and views should be supplied carefully. One's acknowledgements are the bases that probe that the arguments and analysis are acceptable and academic. Thus it helps the research paper be more successful.

This study report will explore the plagiarism problem by looking at a case in a university campus. That is, an overseas student, Igor, committed plagiarism by using another's writing as his own and was caught by his professor. Thus, he felt worried and panic-stricken. The report will give a statement of the problem, suggest some possible solutions, evaluate these solutions and select the best one for further justification. Eventually, some recommendations of preventing plagiarism will be included in the conclusions.

\section{Statement of the problem}

Definition: Igor, a student from Russia, committed plagiarism by submitting

his friend's research paper as his own. This assignment caused his professor's serious doubts. Igor felt sick and panic-stricken when he was asked to write an abstract of the research in front of the professor.

Analysis: Igor, a third-year university student in the U.S hoped to get an excellent grade to graduate one semester early to enter a summer school for his MA in political science. He was worrying those days for not completing his research assignment at almost the end of the semester. When he told his friend, George, about the problem, George offered to write him an essay for \$50 in return. Igor was tempted and accepted the "assistance". However, after submission, this writing caused his professor's great suspicion, since it was different from what he had done before. When the professor asked him to write an abstract, he could not give the main ideas in the research. Eventually, the professor found out about his plagiarism. And now he is having a hard time. 


\section{Suggestion of possible solutions}

Igor can tell the professor the truth, apologize to him and ask for a resubmission.

Igor can stick to his story and deny the plagiarism.

Igor can leave the university immediately and go back to his country.

\section{Evaluation of possible solutions}

Solution A: Igor can tell the professor the truth, apologize to him and ask for a resubmit.

1). Advantages: He will show that he is an honest man; it is not his nature to plagiarize. The professor will give him another chance to submit the assignment and he can learn a lesson from it.

2). Disadvantages: The professor may not accept his apology and fail him or to get him a punishment from the university.

Solution B: Igor can stick to his story and deny committing plagiarism.

1). Advantages: The professor may not discover the plagiarism and Igor will get a high grade.

2). Disadvantages: If the professor can prove his plagiarism, Igor will receive a serious result so that he may lose respect from others and feel immoral.

Solution C: Igor can leave the university and go back to his country.

1). Advantages: He may feel relieved in spirit without facing the reality and can study in another country without having any punishment.

2). Disadvantages: He will lose the chance to study in America for his degree. At the same he will lose respect from his family and friends when he goes back without any certificates.

\section{Selection of Solution}

1). Choice. Confronting his problem, apologizing to the professor and asking for a resubmission are the best of these solutions.

2). Justification. It is wise for Igor to admit to his plagiarism even though he may receive a penalty, because "the instructor has an obligation to investigate and determine the truth" according to University of Manitoba, (N.D). It is possible that the university will punish him, in such as having his offence recorded or failing him one semester. However, as long as he can initiatively realize his violation and expect to rectify it, the professor may allow him to do the research again. Schulman (1998) states, that student should be offered another chance rather than merely imposing punishment on them. Moreover, he has to be responsible for his future study by demonstrating his honesty to the university in correspondence with "the burden of proof is on the university", as stated by University of Manitoba, (N.D). Since Schulman (1998) explains, their first academic offence ought not to prevent them from their future study. Therefore, Igor should confront the problem, apologize to the professor and ask for a resubmission. Then he can continue his study the next semester.

\section{Conclusions and recommendations}

Plagiarism is one part of the general academic immorality. It is more widespread than before as people are struggling for advanced scholarly requirements, especially in universities. Generally, plagiarism is hard to be detected since it requires reasonable labor and time, as Martin (1992) describes, professionals have to read each writing many times to find out whether there is any copying from published materials. Moreover, people are likely to commit plagiarism because they take different attitudes towards plagiarism. Igor, for example, thought that using other people's ideas could help him to achieve criteria. Therefore, to create an honest academic environment, firstly, "universities, faculties and departments need to have clear and well-published policies on plagiarism with examples of correct and incorrect citations" (Martin, 1992). Secondly, some focus should be put on getting offenders understand plagiarism rather than applying penalties to them. Finally, it may be 
necessary to motivate researchers to think creatively and independently in the process of research, as Martin (1992) says, "they should be encouraged to model themselves on the best thinkers".

Common knowledge including various scientific theories and proved discoveries can be included in preparing one's own research. However, any part of those academic research inserted into one's own paper should be properly quoted and cited. One must acknowledge the origin of an idea if it is not common knowledge. It may be hard to define exactly what common knowledge is in one's research is, he/she may go to consult lacquerers or professors. Or it is unnecessary to provide a reference if one is not so certain for it.

To prevent student plagiarism papers, it is to main the academic ethics and academic integrity, Many universities often take a number of measures to deal with those problems by demanding a written information, honest statement, academic norms of training, strictly electronic exploration assistance, illegal punishment, etc. Besides, it is correct to say that instructors should be involved in the field of knowledge to students. If they can seriously be responsible, they are most likely to detect plagiarism of papers, give timely guidance to students in a timely manner to correct or avoid significant adverse impact on the school and students.

As a result of the diversity of academic paper plagiarism, it is impossible to set up an absolute standard of judgment. However, it's important that people should establish a good sense of acknowledging and citing materials properly. One can use someone's ideas, but putting them in his/her own words. This is probably the skill he/she will use most when incorporating sources into the writing. Although one uses his/her own words to paraphrase, he/she must still acknowledge the source of the information.

Finally, special emphasis is needed to prevent student plagiarism paper, which is a comprehensive project. The above-mentioned measures are needed to be used within academic institutions. Universities can clearly inform students about plagiarism of school rules, to teach students the proper academic standards so that students will not be accidentally commit plagiarism because of ignorance and foul.

\section{References}

[1] Martin, Brian 1992, Plagiarism By University Students: the Problem and Some Proposals, published in Tertangala (University of Wollongong Students' Representative Council), 20July - 3 August 1992,p.20.http:/ www.uow.edu.au/arts/sts/bmartin/pubs/92tert.html

[2] University of Manitoba - Student Advocacy, 'Cheating, Plagiarism \& Fraud' , http:/www.umanitoba.ca/student/advocacy/cheating-plagiarism-fraud.shtml-39k-31mar

[3] Schulman, M. 1991, 'Telling Students about Copyright', Found in Cultures in Contrast, University of Michigan Press, Michigan.

[4] 'How Can I Prevent Plagiarism?' www.lis.uiuc.edu/ janicke/plagiary.htm - 7k 